\title{
A STUDY OF PREVALENCE AND OTHER CHARACTERISTICS OF ADULT ADHD IN SUBSTANCE USE DISORDER PATIENTS: A CROSS SECTIONAL STUDY
} \author{
Khaled Ahmed Abdel Azim6', Mohamed Shahdah7, Ahmed Mohamed El Melegy ${ }^{8}$ \\ ${ }^{1}$ Lecturer, Department of Psychiatry, Faculty of Medicine, Zagazig University. \\ ${ }^{2}$ Assistant Professor, Department of Psychiatry, Faculty of Medicine, Mansoura University. \\ ${ }^{3}$ Assistant Professor, Department of Psychiatry, Faculty of Medicine, Al-Azhar University. \\ ${ }^{4}$ Assistant Professor, Department of Psychiatry, Faculty of Medicine, Zagazig University. \\ ${ }^{5}$ Assistant Professor, Department of Psychiatry, Faculty of Medicine, Al-Azhar University. \\ ${ }^{6}$ Assistant Professor, Department of Psychiatry, Faculty of Medicine, Ain Shams University. \\ ${ }^{7}$ Assistant Professor, Department of Psychiatry, Faculty of Medicine, Mansoura University. \\ ${ }^{8}$ Specialist Clinical Pathology, Faculty of Medicine, Zagazig University.
}

Dalia Mokhtar Khalili ${ }^{1}$ Khalid Saad Sherra², Hesham Mahmoud Abuhegazy3, Nagda M. El masry4, Ahmed Kamel5,

ABSTRACT

\section{AIM}

To study the prevalence of Adult ADHD in Substance Use Disorder patients and to study the Characteristics in Substance Use Disorder patients with and without Adult ADHD.

\section{METHODS}

The study was conducted in the Psychiatry Department of Mansoura University Hospital, Egypt. Both inpatients and outpatients who screened positive for any one of the substances like Alcohol, Opioids, Amphetamine or Cannabis were approached to enter the study. Out of these, those patients who gave informed consent and satisfied the inclusion and exclusion criteria and met the DSM IV TR diagnosis for substance use disorder for dependence or abuse, entered the study and completed the patient intake form; 100 such consecutive patients were screened for symptoms of Adult ADHD by administering the first six questions of Part A of Arabic version of Adult ADHD self-report scale-VI.I (ASRS- VI.I) symptom checklist. Only the first six questions which are found to be the most predictive of symptoms were included for screening. Those patients who answered positive for four or more questions were further interviewed using Diagnostic Interview of Adult ADHD (DIVA) to make a diagnosis of Adult ADHD in these patients; 97 patients completed all the parts of study questionnaire. The prevalence of the Adult ADHD inpatients with substance use disorders was calculated and relationship between the groups - Substance use disorder with ADHD (SUD with Adult ADHD) and Substance use disorders without ADHD (SUD without Adult ADHD) were studied and results statistically analysed using SPSS software.

\section{RESULTS}

The prevalence of Adult ADHD among the substance use disorder patients was found to be $27.8 \%$, which constituted approximately more than one-fourth of the study population. The groups did not differ significantly in terms of socio-demographic profile. The SUD with Adult ADHD had significantly mean early age of onset 20 years Vs 32 years in the other group. This group also had mean longer duration of substance use 12.37 Vs 4.31 years and higher relapse rate 3.91 times compared to 1.11 times in SUD without Adult ADHD group.

\section{CONCLUSION}

The prevalence of Adult ADHD in Substance use disorder patient is high. Comorbid Adult ADHD in substance use disorder patients prolongs the course of substance use disorder and contributes to high relapse rates in these groups of patients.

\section{KEYWORDS}

Substance Use Disorders - Adult ADHD- Characteristics.

HOW TO CITE THIS ARTICLE: Khalil DM, Sherra KS, Abuhegazy HM, et al. A study of prevalence and other characteristics of adult ADHD in substance use disorder patients: a cross sectional study. J. Evolution Med. Dent. Sci. 016;5(46):2870-2873, DOI: $10.14260 /$ jemds/2016/669

\section{INTRODUCTION}

Adult ADHD has only recently become the focus of widespread clinical attention. ${ }^{1}$ especially in developing countries. The data on prevalence of Adult ADHD are limited and it may affect up to $5 \%$ of adult population. ${ }^{2}$

Financial or Other, Competing Interest: None.

Submission 07-03-2016, Peer Review 19-05-2016,

Acceptance 25-05-2016, Published 07-06-2016.

Corresponding Author:

Dalia Mokhtar Khalil,

\#14, Mahmoudshahin-Alsalam Sidnawy,

Zagazig, Egypt.

E-mail: dmokhtar173156@yahoo.com

DOI: $10.14260 /$ jemds/2016/669
But the prevalence is much greater in the substance use disorder patients and many studies consistently show that.3,4 $15 \%$ to $25 \%$ of adults with a lifetime history of SUD may have ADHD. 5

The study of comorbidity between SUD and Adult ADHD is relevant to both research and clinical practice and understanding the relationship between two disorders is very essential. SUD patients with ADHD are reported to have worse treatment outcomes for both SUD. ${ }^{6}$ and ADHD. ${ }^{7}$ ADHD is associated with more severe and longer duration of SUD, lower remission rates and more difficulty in SUD treatments.8,9,10,11 Adults with both ADHD and SUD have been reported to have earlier onset of substance abuse relative to adults without ADHD. 12 
The identification of specific risk factors of SUD within ADHD may permit targeted treatments for both disorders at earlier stages of their expression, potentially dampening the morbidity, disability and poor long-term prognosis in adolescents and adults with this comorbidity.13,14

Hence, we did a cross-sectional analysis and studied the groups, SUD with and without ADHD to determine how the groups differed in terms of their socio-demographic profile and some of the characteristics which can determine the severity and chronicity of the substance use disorder patients.

\section{METHODS}

\section{Subjects}

The study was conducted from February to August 2015 and was approved by the Ethical Committee. Patients attending the outpatient and inpatient unit in the Psychiatry Department of Mansoura University Hospital, Egypt, who screened positive for one or more of the substances like Alcohol, Opioids, Amphetamine, stimulants, Cannabis were approached to participate in the study. Written informed consent was obtained from all the participants. The patients were interviewed by a trained professional and those who satisfied the inclusion criteria, age between 18 to 65 years and current DSM IV TR diagnosis of substance use disorders and exclusion criteria, not affected by any severe mental or neurological disorders like psychosis, affective disorders, Dementia, Parkinson's, entered the study.

100 consecutive patients were enrolled into the study and requested to complete all parts of the patient intake form which consisted of demographic data, details regarding their substance use, screening questions for Adult ADHD from the Arabic version of the Adult ADHD self-report scale. 15 The patients were further subjected to Diagnostic Interview for ADHD in Adults (DIVA) for making a final diagnosis. Out of 100 , 97 patients completed all parts of the study. Three patients dropped out due to non-availability of an informant to complete DIVA and due to physical health reasons.

\section{Screening for Substance Abuse}

Alcohol was measured by enzymatic method by oxidation to acetaldehyde with $\mathrm{NADH}^{+}$, a reaction catalysed by alcohol dehydrogenase ADH.16
For qualitative assessment of opiate, cocaine (Benzylecgonine) and amphetamine in urine, an initial immunoassay screening test was carried on with a cut-off of (300 ng/mL, $300 \mathrm{ng} / \mathrm{mL}$ and $500 \mathrm{ng} / \mathrm{mL}$ ) respectively, and confirmatory test of gas chromatography-mass spectroscopy (GC-MS) was done if needed. ${ }^{17}$

For opiate, urine is treated first with acid to hydrolyse the glucuronides and with hydroxylamine, and then extracted with solid-phase extraction column. For cocaine, derivatives of benzoylecgonine after extraction from urine were analysed with deuterated internal standard in the selected ionmonitoring mode.

\section{Assessment Measures}

Screening for Adult ADHD was done by Arabic version of Adult ADHD self-report scale-VI.I (ASRS-VI.I) symptom checklist. Only the first six questions which are found to be the most predictive of symptoms were included for screening. ${ }^{18,19}$

Diagnostic interview for ADHD in Adults (DIVA 2.0) is a structured interview for ADHD in adults. ${ }^{20,21}$ It is divided into three parts that are each applied to both childhood and adulthood, the criteria for Attention deficit (A1), the criteria for Hyperactivity-Impulsivity (A2), the age of onset and impairment accounted for by ADHD symptoms. The patients were diagnosed as having Adult ADHD if they scored six or more for each of the symptom domains of Attention deficit (A) and Hyperactivity-Impulsivity (HI) in childhood and during adult life with evidence of life-long persistent course with impairment in at least two situations and these symptoms not explained by another psychiatric disorder.

\section{Statistical Analysis}

Statistical analysis was done using IBMSPSS 23 program and methods according to Landau and Everitt (2004). ${ }^{22}$

\section{RESULTS}

Out of the 97 participants who completed the study, 27 were diagnosed to have comorbid Adult ADHD. A cross-sectional prevalence rate was calculated to be $27.8 \%$. The group SUD with ADHD had 27 subjects and without ADHD had 70 subjects. The two groups were then compared and statistically analysed.

\begin{tabular}{|c|c|c|c|c|c|}
\hline \multicolumn{2}{|c|}{ Groups } & SUD without ADHD & SUD with ADHD & Total & $\mathbf{P}$ \\
\hline \multicolumn{2}{|c|}{ No. of Patients } & 70 & 27 & 97 & \\
\hline \multicolumn{2}{|c|}{ Male/Female } & $66 / 4$ & $24 / 3$ & $90 / 7$ & 0.451 \\
\hline \multicolumn{2}{|c|}{ Age (+SD) in years } & $38.09+5.84$ & $34.17+5.84$ & $40.92+5.84$ & 0.8459 \\
\hline \multirow{3}{*}{ Residence } & Urban & $19(27.1 \%)$ & $17(63.0 \%)$ & $39(45.4 \%)$ & 0.2721 \\
\hline & Suburban & $13(18.6 \%)$ & $7(25.9 \%)$ & $20(23.3 \%)$ & 0.3743 \\
\hline & Rural & $38(54.3 \%)$ & $3(11.1 \%)$ & $37(43.0 \%)$ & 0.1024 \\
\hline \multirow{4}{*}{ Education } & Primary & $6(8.6 \%)$ & $1(3.7 \%)$ & $7(8.1 \%)$ & 0.1701 \\
\hline & Preparatory & $38(54.3 \%)$ & $4(14.8 \%)$ & $38(44.2 \%)$ & 0.2414 \\
\hline & Secondary & $20(28.6 \%)$ & $19(70.4 \%)$ & $40(46.5 \%)$ & 0.2723 \\
\hline & University & $6(8.6 \%)$ & $3(11.1 \%)$ & $11(12.8 \%)$ & 0.4814 \\
\hline \multirow{3}{*}{ Marital status } & Married & $32(45.7 \%)$ & $5(18.5 \%)$ & $34(39.5 \%)$ & 0.2518 \\
\hline & Unmarried & $10(14.3 \%)$ & $10(37.0 \%)$ & $22(25.8 \%)$ & 0.3619 \\
\hline & Divorced & $28(4.0 \%)$ & $12(44.4 \%)$ & $40(46.5 \%)$ & 0.8732 \\
\hline \multirow{2}{*}{ Employment } & Employed & $29(41.4 \%)$ & $23(85.2 \%)$ & $54(62.8 \%)$ & 0.5424 \\
\hline & Unemployed & $41(58.6 \%)$ & $4(14.8 \%)$ & $42(48.8 \%)$ & 0.2432 \\
\hline \multirow{3}{*}{ Socioeconomic status } & Low & $32(45.7 \%)$ & $1(3.7 .9 \%)$ & $29(33.7 \%)$ & $0.012^{*}$ \\
\hline & Average & $33(47.1 \%)$ & $11(40.7 \%)$ & $43(50 \%)$ & 0.812 \\
\hline & High & $5(7.1 \%)$ & $15(55.5 \%)$ & $24(16.3 \%)$ & $0.032^{*}$ \\
\hline \multicolumn{6}{|c|}{ Table 1} \\
\hline
\end{tabular}


Table 1 shows the comparison between two groups. The groups had excess of male subjects and few females but the difference not statistically significant. The groups were comparable in terms of age, area of residence, level of education and marital status; $45.7 \%$ of patients from SUD without ADHD belonged to low socioeconomic status and 55.5\% of SUD with ADHD were from high socioeconomic status and the result was statistically significant at $95 \%$ confidence interval.

\begin{tabular}{|c|c|c|c|c|}
\hline Groups & SUD without ADHD & SUD with ADHD & Total & $\mathbf{P}$ \\
\hline Age of onset of SUD in years & $32.77+6.25$ & $20.15+2.1$ & $31.44+4.2$ & $0.006^{*}$ \\
\hline Duration of SUD in years & $4.31+4.1$ & $12.37+6.07$ & $8.09+5.5$ & $0.012^{*}$ \\
\hline Average number of hospitalization & $1.55+0.83$ & $3.15+1.94$ & $2.38+1.04$ & 0.278 \\
\hline Hospitalization days & $66.67+33.6$ & $92.63+15.36$ & $84.99+25.48$ & 0.456 \\
\hline Average relapse times & $1.11+1.2$ & $3.91+1.4$ & $1.89+1.25$ & $0.056^{*}$ \\
\hline Total duration of abstained days & $67.5+33.31$ & $89.66+15.69$ & $84.37+24.5$ & 0.545 \\
\hline Mean days of abstinence in each abstinent period & $54+29.48$ & $19.84+11.2$ & & 0.169 \\
\hline \multicolumn{5}{|c|}{ Table 2} \\
\hline
\end{tabular}

Table 2 shows the comparison of the two groups, SUD with and without ADHD on the characteristics which can determine the onset and longitudinal course of the illness. SUD with ADHD group had an early age of onset of substance use 20.15 years when compared to SUD without ADHD who had a mean age of onset at 32.77 years.

The total duration of substance use among SUD with ADHD was 12.37 years, which was longer than 4.31 years in patients with SUD without ADHD.

SUD with ADHD had more relapse rate. They relapsed on an average 3.91 times compared to 1.11 times in SUD without ADHD.

The two groups were also compared for the average number of hospitalization and average total number of days spent in hospital. The SUD with ADHD had an increased number of hospital admissions 3.15 Vs 1.55 times and more days spent in hospital 92.63 Vs 66.67 days, but the difference was not statistically significant.

The SUD with ADHD had a shorter abstinent duration per abstinent period; 19.84 Vs 54 days in the SUD without ADHD group.

\section{DISCUSSION}

The current findings indicate the prevalence of comorbid Adult ADHD among SUD patients in our study population was much higher $27.8 \%$ compared to the prevalence rate in the general population. This prevalence rate was comparable to the result of the recent meta-analysis by Van Emmerik-Van Oortmersser et al 2013 (Based on 12 studies in adult treatment seeking SUD patients). ${ }^{23}$ which reported the pooled Adult ADHD prevalence rate at $23.3 \%$. The results are also comparable to another study conducted in Egypt by A. Abdelkarim et al 2013.24 which quoted a prevalence rate of $35.3 \%$. The slight variations in the prevalence rate could be attributed to the different diagnostic instruments used to make a diagnosis of Adult ADHD in SUD patients.

Our study showed no significant difference between the two groups in terms of age, area of residence, educational level, marital status or employment, but SUD with ADHD was more prevalent in the high socioeconomic status. Previous studies have shown that Adult ADHD was more prevalent in high income countries $4.2 \%$ and lower prevalence in lower income countries. ${ }^{19}$ and other studies show that there is no difference between SUD with and without ADHD in terms of their socioeconomic status. ${ }^{25}$ The result needs further evaluation and research to determine if the socioeconomic status is a determinant for increased Adult ADHD prevalence in SUD patients.
The mean age of onset in SUD with ADHD was 20 years, which replicate the findings by Wilens et al 2004.4 who showed that the age of onset was 19 years in their study population. But the mean age of onset in SUD without ADHD patients in our study was 32 years compared to 22 years by Wilens et al 2004. ${ }^{4}$ Hence in our study group SUD with ADHD patients had started abusing substances 10 years earlier than their counterparts without ADHD.

The total duration of substance use was significantly much longer in SUD with ADHD subjects, 12 years at the time of presentation compared to 4 years in the SUD without ADHD. This is similar to the findings by Wilens et al $2004 .{ }^{4}$ who found that the duration of the substance abuse was longer in adults with ADHD than in those without.

One of the important result of the study is that the SUD with ADHD had a higher relapse rate 3.91 times compared to 1.11 times in the other group, which was statistically significant. This proves that the symptoms of inattention, hyperactivity and impulsiveness play a major role in SUD patients to determine their compliance to treatment and high rate of relapse in this group of patients.

The average number of hospitalizations was more, 3.15 times in SUD with ADHD subjects compared to 1.55 time in those without ADHD. Though the difference is not significant it was similar to other studies. ${ }^{24}$ which showed higher number of hospital admissions in SUD with ADHD group compared to those without.

Patients in SUD with ADHD group were abstinent for an average 19.84 days per abstinent period compared to 54 days in the other group. Though the result not significant which may be due to small sample size, gives an indication of the chronic nature of SUD in this group.

\section{LIMITATIONS}

The findings of this study needs to be viewed in light of some of the methodological limitations. We had a small sample size. The SUD category represented broad range of substance use from alcohol use to substance dependence and we would not be able to differentiate the effect of Adult ADHD in accordance to the substance used. The diagnosis obtained by structured interview were based on the retrospective recall of illness such as the age of onset and duration of illness, which are subject to recall bias. Another limitation is the cross-sectional design of the study, which prevents us from making a causal inferences on the association that we found.

\section{CONCLUSION}

Despite these limitations, our study data supports the previous studies which clearly indicate high prevalence rate of Adult 
ADHD in SUD patients. The comorbidity of Adult ADHD clearly influences the onset and course of the substance use in these individuals leading to prolonged course of the disorder and higher relapse rates, hence posing greater challenges for management and increasing burden on the mental health resources. There is an urgent need for all mental health professionals to routinely screen all the substance use disorder patients for symptoms of Adult ADHD and focus on treatment of both the disorders concurrently to achieve greater benefits in treating substance use disorders.

\section{REFERENCES}

1. Wilens TE, Faraone SV, Biederman J. Attentiondeficit/hyperactivity disorder in adults. JAMA 2004;292:619-23.

2. Biederman J, Wilens T, Mick E, et al. Psychoactive substance use disorders in adults with attention deficit hyperactivity disorder (ADHD): effects of ADHD and psychiatric comorbidity. Am J Psychiatry 1995;152(11):1652-8.

3. Wilens T, Prince J, Biederman J, et al. Attention deficit hyperactivity disorder and comorbid substance use disorders in adults. Psychiatr Serv 1995;46(8):761-3.

4. Wilens TE, Dodson W. A clinical perspective of attentiondeficit hyperactivity disorder into adulthood. J Clin Psychiatry 2004;65:1301-13.

5. Wilens T. ADHD and substance abuse. In: Spencer T, ed. Adult ADHD. Philadelphia, Pa: Psychiatric Clinics of North America. In press.

6. Arias AJ, Gelernter J, Chan G, et al. Correlates of cooccurring ADHD in drug-dependent subjects: prevalence and features of substance dependence and psychiatric disorders. Addict Behav 2008;33(9):1199-207.

7. Castells X, Ramos-Quiroga JA, Rigau D, et al. Efficacy of methylphenidate for adults with attention-deficit hyperactivity disorder. A meta-regression analysis. CNS Drugs 2011;25(2):157-69.

8. Carroll KM, Rounsaville BJ. History and significance of childhood attention deficit disorder in treatmentseeking cocaine abusers. Compr Psychiatry 1993;34(2):75-82.

9. Eyre SL, Rounsaville BJ, Kleber HD. History of childhood hyperactivity in a clinic population of opiate addicts. J Nerv Ment Dis 1982;170(9):522-9.

10. Biederman J, Wilens TE, Mick E, et al. Does attentiondeficit hyperactivity disorder impact the developmental course of drug and alcohol abuse and dependence? Biol Psychiatry 1998;44(4):269-73.

11. Wilens T, Biederman J, Mick E. Does ADHD affect the course of substance abuse? Findingsfrom a sample of adults with and without ADHD. Am J Addict 1998;7(2):156-63.

12. Wilens TE, Biederman J, Abrantes AM, et al. Clinical characteristics of psychiatrically referred adolescent outpatients with substance use disorder. J Am Acad Child Adolesc Psychiatry 1997;36(7):941-7.
13. Mannuzza S, Klein RG, Bessler A, et al. Adult outcome of hyperactive boys: educational achievement, occupational rank, and psychiatric status. Arch Gen Psychiatry 1993;50(7):565-76.

14. Weiss G, Hechtman L, Milroy T, et al. Psychiatric status of hyperactives as adults: a controlled prospective 15-year follow-up of 63 hyperactive children. J Am Acad Child Psychiatry 1985;24(2):211-20.

15. Kessler RC, Adler L, Ames M, et al. The world health organization adult ADHD self-report scale (ASRS): a short screening scale foruse in the general population. Psychol Med 2005;35(2):245-56.

16. Dubowski KM, Caplan YH. Alcohol testing in the workplace. In: Garriott JC, ed. Medicolegal aspects of alcohol. Tucson, AZ: Lawers \& Judges Publishing Co, 1996;439-75.

17. Kwong TC, Chamberlain RT, Frederick DL, et al. Critical issue in urinanalysis of abused substances: report of the substance-abuse testing committee. Clin Chem 1988;34(3):605-32.

18. Kessler RC, Adler LA, Gruber MJ, et al. Validity of the world health organization adult ADHD self-report scale (ASRS) screener in a representative sample of health plan members. Int $J$ Methods Psychiatr Res 2007;16(2):52-65.

19. Fayyad J, De Graaf R, Kessler R, et al. Cross-national prevalence and correlates of adult attention-deficit hyperactivity disorder. BJP 2007;190:402-9.

20. Kooij JJ, Buitelaar JK, van den Oord EJ, et al. Internal and external validity of attention-deficit hyperactivity disorder in a population-based sample of adults. Psychological Medicine 2005;35(6):817-27.

21. Kooij JJS, Boonstra AM, Willemsen-Swinkels SHN, et al. Reliability, validity, and utility of instruments for selfreport and informant report regarding symptoms of attention-de fi cit/hyperactivity disorder (ADHD) in adult patients. J Atten Disord 2008;11(4):445-58.

22. Landau S, Everitt BS. A handbook of statistical analysis using SPSS, 2004, by Chapman and Hall/CRC Press LLC, A CRC press company Boca Raton, London New York, Washington, D.C, Chapter 3, page 71-98.

23. Van Emmerik-van Oortmerssen $K$, van de Glind G, Koeter MW, et al. Psychiatric comorbidity in treatment seeking substance use disorder patients with and without ADHD: results of the IASP study. Addiction 2014;109(2):262-72.

24. Abdelkarim A, Salama H, Abdel Latif S, et al. 2628prevalence and characteristics of adult attention-deficit hyperactivity disorder among substance use inpatients. European Congress of Psychiatry 2013;28(1):1.

25. Timothy E Wilens, Anne Kwon, Sarah Tanguay, et al. Characteristics of adults with attention deficit hyperactivity disorder plus substance use disorder: the role of psychiatric comorbidity. Am J Addict 2005;14(4):319-27. 